\title{
DIREITO FUNDAMENTAL À ASSISTÊNCIA SOCIAL: CONSELHOS GESTORES SERVIÇO DE REPÚBLICA PARA EGRESSOS DE UNIDADES DE ACOLHIMENTO
}

\author{
FUNDAMENTAL RIGHT TO SOCIAL ASSISTANCE: MANAGEMENT COUNCILS AND SHELTER \\ SERVICE FOR YOUNG PEOPLE
}

Antonio Jorge Pereira Junior ${ }^{1}$

Thiago Pessoa Colares ${ }^{2}$

\begin{abstract}
Resumo: $O$ presente estudo trata do direito fundamental de crianças e jovens à assistência social como fundamento para exigência da prestação do serviço de repúblicas para egressos de Unidades de Acolhimento que atingiram a maioridade. Trata, ainda, das atribuições de conselhos gestores de deliberação e controle da implementação de políticas públicas. Por fim, discrimina o modo como deve ser prestado o serviço de repúblicas e analisa como as omissões municipais em dar efetividade às resoluções aprovadas pelos conselhos permite que o Poder Judiciário determine a obrigação de materialização dos direitos fundamentais. O estudo teve como metodologia a realização de pesquisa qualitativa, bibliográfica e documental.
\end{abstract}

Palavras-chave: Direito fundamental à assistência social. Proteção integral infantojuvenil. Repúblicas para jovens. Políticas públicas. Judicialização.

\begin{abstract}
This study deals with the fundamental right of children and young people to social assistance as a basement for demanding the provision of shelter service for young people coming from foster family services that have reached the age of majority. It also deals with the role of councils in deliberating and controlling the implementation of public policies. Finally, it discriminates the way in which the service of republics should be provided and analyzes how the municipal omissions in giving effect to the resolutions approved by the councils allow the Judiciary to determine the obligation of materialization of the fundamental rights. The study had as methodology the accomplishment of qualitative, bibliographical and documentary research.
\end{abstract}

Keywords: Social assistance. Integral protection for children and youth. Shelter service for young people. Public policies. Jurisdictional control.

Recebido em 04 de dezembro de 2018 Avaliado em 06 de dezembro de 2018 (AVALIADOR A) Avaliado em 18 de outubro de 2019 (AVALIADOR B) Aceito em 18 de outubro de 2019

\footnotetext{
Doutor em Direito pela Universidade de São Paulo; Professor no Programa de Mestrado e Doutorado da Universidade de Fortaleza; https://orcid.org/0000-0002-0611-2869; antoniojorge2000@gmail.com

2 Bacharel em Direito pela Universidade de Fortaleza; Advogado; Avenida Washington Soares, 1321, Edson Queiroz, 60811905, Fortaleza, Ceará, Brasil; https://orcid.org/0000-0002-6688-9450; thiago_colares@hotmail.com
} 


\section{Introdução}

O ordenamento jurídico, abrangendo, dentre outros, Constituição Federal (CF), Estatuto da Criança e do Adolescente (ECA), Estatuto da Juventude (EJ) e Lei Orgânica de Assistência Social (LOAS), prevê a existência de direitos fundamentais socioassistenciais assegurados à população infantojuvenil, os quais, constituindo direitos sociais, são passíveis de concretização por meio da execução de políticas públicas (JORGE NETO, 2009, p. 56-57).

Neste âmbito, a legislação prevê também a existência de conselhos deliberativos, colegiados constituídos pelos mais diversos atores da sociedade civil, com a função de discutir a criação de políticas públicas e fiscalizar a aplicação destas ações governamentais no âmbito da assistência social e da infância e juventude.

Havendo, portanto, determinação legal no sentido de entregar aos conselhos gestores o dever de deliberar acerca das políticas públicas a serem executadas pelo Poder Executivo, mediante, inclusive, incorporação de gastos na lei orçamentária, tornam-se cogentes as resoluções aprovadas por aqueles, gerando, até mesmo, a possibilidade de condenação judicial da Administração Pública ao cumprimento das medidas aprovadas pelo colegiado.

Dessa forma, a criação de repúblicas para jovens egressos de unidades de acolhimento, serviço socioassistencial definido por meio de resoluções de conselhos gestores, constitui serviço de implementação obrigatória pelos entes municipais. Eventual omissão gera a possibilidade de controle judicial, a partir do qual sobressairá o dever de implementação de tal política.

A presente pesquisa pretende, portanto, analisar as questões referentes à efetivação dos direitos fundamentais socioassistenciais de crianças e de jovens por meio da execução de políticas públicas, especificamente aquelas deliberadas pelos conselhos de assistência social e da infância e juventude, com foco na criação de repúblicas. Visa, ainda, enfrentar o tema da possibilidade de exercício do controle judicial em razão de omissão da Administração Pública em promover ações governamentais.

Para alcançar seus fins, o estudo teve como abordagem a realização de pesquisa qualitativa, com foco na análise das diretrizes legais para a materialização dos direitos fundamentais por meio das deliberações promovidas pelos conselhos gestores, na discriminação da forma como o serviço de repúblicas deve ser fornecido e no exame do controle jurisdicional de políticas públicas.

No mais, pautou-se em pesquisa bibliográfica, a partir do exame de artigos científicos, capítulos de livros e dissertações voltadas às temáticas de direitos fundamentais, políticas públicas e direitos infantojuvenis; e documental, destacando-se, além da análise de julgados do Superior Tribunal de Justiça (STJ), a verificação do documento Orientações Técnicas: Serviços de Acolhimento para Crianças e Adolescentes, aprovado pela Resolução Conjunta CNAS/CONANDA n. 1, de 18 de junho de 2009. 


\section{Direitos fundamentais à proteção integral infantojuvenil e à assistência social}

A CF prevê a proteção a crianças e a jovens como um direito social, existindo dispositivos protetivos tanto no âmbito da assistência social (art. 203, I e II, CF) quanto da infância e juventude (art. 227, CF) (BRASIL, 1988).

A assistência social, de acordo com a redação do art. 203 da CF, pode ser entendida como uma garantia ao recebimento de prestações materiais por parte do Estado, voltando-se apenas a pessoas em situação de vulnerabilidade (BRASIL, 1988).

Nesse contexto, o constituinte originário tratou de elencar os objetivos da assistência social, dispostos no art. 203, constando, entre outros, "a proteção à família, à maternidade, à infância, à adolescência e à velhice" (inciso I) e "o amparo às crianças e adolescentes carentes" (inciso II), fazendo-se notória a ênfase dada à proteção das crianças e dos adolescentes.

Além disso, a Lei n. 8.742/1993 (LOAS) prevê como serviços socioassistenciais os programas de amparo voltados às crianças e aos adolescentes em situação de risco pessoal e social, conforme disposto no art. $23, \mathbb{S} 1^{\circ}$, sendo a criação de tais programas de responsabilidade dos Municípios, nos termos do art. 15, V, da legislação mencionada (BRASIL, 1993). Naturalmente, sendo lei preexistente ao Estatuto da Juventude (EJ), de 2013, a LOAS não se refere diretamente ao "jovem" enquanto sujeito qualificado como pessoa entre 15 e 29 anos de idade. Por isso, também nesse estudo, optou-se por desenvolver a abordagem mormente referindo-se a criança e adolescente. No momento oportuno se fará menção expressa ao EJ.

O direito à assistência social, portanto, possui clara conexão com a disposição de proteção integral infantojuvenil, a qual reconhece crianças e adolescentes como sujeitos de direitos, porém sob a ótica de personalidades e identidades em formação. Tal peculiaridade, portanto, faz com que se diferenciem e mereçam especial entrega de prestações por parte da família, da sociedade e do Estado (LOPES, 2012, p. 100).

Nesse contexto, convém salientar que o direito à assistência social e à proteção de crianças e adolescentes, ainda que não se encontrem entre as hipóteses do art. $5^{\circ}$ da CF, devem ser entendidos como direitos fundamentais, uma vez que "apesar de se encontrarem fora do catálogo, por seu conteúdo e por sua importância podem ser equiparados aos direitos formalmente (e materialmente) fundamentais." (SARLET, 2011, p. 80).

Tendo em vista, ainda, a importância dos direitos mencionados, cujo escopo é proteger pessoas em situação de vulnerabilidade, e o viés de absoluta prioridade (art. 227, CF) (BRASIL, 1988) à efetivação de direitos inerentes a este grupo específico (crianças e adolescentes), denota-se o caráter de fundamentalidade da assistência social e da proteção integral infantojuvenil.

Em complemento, o próprio art. $5^{\circ}$ da $\mathrm{CF}$, em seu $\$ 2^{\circ}$, dispõe que: "os direitos e garantias expressos nesta Constituição não excluem outros decorrentes do regime e dos princípios por ela adotados, ou dos tratados internacionais em que a República Federativa do Brasil seja parte”. Dessa 
forma, fica claro que os direitos fundamentais não estão previstos apenas no rol do art. $5^{\circ}$, fazendose necessário realizar uma interpretação sistemática de todo o ordenamento pátrio.

Saliente-se que a importância da assunção dos direitos socioassistenciais de crianças e adolescentes como sendo direitos de caráter fundamental se revela oportuno, dentre outras razões, diante da aplicação imediata prevista no art. $5^{\circ}$, $₫ 1^{\circ}$, da CF (BULOS, 2012, p. 414-415), bem como pelo seu valor de cláusula pétrea (art. 60, $\$ 4^{\circ}$, IV, CF) (BRASIL, 1988), ${ }^{3}$ vedando-se eventual tentativa de supressão.

Ademais, a noção de direito fundamental social passa também pela visão de que, para sua concretização, torna-se necessário que uma prestação material seja fornecida, surgindo, em contrapartida, um dever fundamental, conforme disposto a seguir (CASTRO, 2010, p. 43-44):

[...] Daí resulta a percepção de que a idéia de direitos fundamentais, na ótica do constitucionalismo comunitário, impõe a contrapartida de deveres fundamentais, tanto deveres fundamentais autônomos e primariamente ditados pela Constituição e pelas leis de implementação constitucional (a exemplo do dever genérico de pagar tributo, do voto obrigatório, da prestação do serviço militar etc., emergentes, respectivamente, dos arts. 145 e segs., 14, parágrafo primeiro, e 143 da Carta Política de 1988), quanto deveres fundamentais associados a direitos fundamentais, como por exemplo o dever dos pais de assistir globalmente aos filhos, que corresponde ao (sic) direitos dos filhos à assistência de ambos os genitores no âmbito da família, segundo o disposto nos artigos 226 , $\$ 5^{\circ}$, e 227 da Constituição da República [...]

Dessa forma, para concretizar o direito fundamental à proteção da infância e da juventude, faz-se necessário que a família, conforme mencionado no trecho acima citado, mas também que a sociedade e o Estado, como prevê o art. 227 da CF (BRASIL, 1988), prestem um dever fundamental de cuidado em relação às pessoas menores de idade, estendendo-se, por força do EJ, até os vinte e nove anos incompletos.

Todo o embasamento constitucional e legal acima exposto possibilita a compreensão de que os direitos infantojuvenis, no âmbito da doutrina da proteção integral, devem ser promovidos pela família, pela sociedade e pelo Estado, correspondendo a estes um dever fundamental de entregar a devida prestação material a crianças e a adolescentes.

Neste sentido, cabe especificamente ao Estado, tendo em vista não só o direito fundamental à proteção da infância e da juventude, mas também o direito fundamental à assistência social, promover políticas públicas voltadas à superação de situações de risco em que crianças e jovens estejam envolvidos. Além disso, conforme será explanado a seguir, os entes estatais devem dar

\footnotetext{
$\overline{3}$ No que pese o art. $60, \S 4^{\circ}$, da Constituição Federal se refira apenas aos direitos e garantias individuais como cláusula pétrea, o entendimento que prevalece atualmente é o de que não só os direitos individuais, mas os direitos fundamentais (que vão muito além das hipóteses previstas no art. $5^{\circ}$ da CF/88, conforme já tratado) se revestem dessa característica (BONAVIDES, 2004, p. 640-642).
} 
prioridade à execução de políticas infantojuvenis, garantindo, em primeiro lugar, a materialização de direitos deste público, em razão de sua vulnerabilidade.

\section{Prioridade de formulação de políticas públicas para a população infantojuvenil}

O ECA especifica, em seu art. 4, ${ }^{\mathrm{T}}$ a prioridade absoluta garantida pela Constituição às crianças e aos adolescentes em uma série de situações que vão desde o atendimento em serviços públicos até a formulação de políticas públicas.

Essa garantia de prioridade, obviamente, tem uma razão de ser, a qual condiz com a situação da criança e do adolescente como indivíduos vulneráveis, em estado de desenvolvimento, merecendo, portanto, tratamento diferenciado e proteção integral por parte do Poder Público (AMIN, 2013, p. 60).

A fim de viabilizar a proteção integral, a lei prevê preferência na formulação e na execução de políticas públicas infantojuvenis, ou seja, maior cuidado na promoção de ações governamentais coordenadas com escopo de materializar os direitos à vida, à saúde, à educação e aos demais previstos no ECA (BUCCI, 2006, p. 14).

A interpretação da garantia de prioridade deve se dar em consonância com o princípio do interesse superior da criança e do adolescente, mediante atendimento aos direitos infantojuvenis "sem prejuízo da consideração que for devida a outros interesses legítimos no âmbito da pluralidade dos interesses presentes no caso concreto", conforme disposto no art. 100, parágrafo único, IV, do ECA (BRASIL, 1990).

O caráter absoluto da garantia de prioridade infantojuvenil prevalece, portanto, em relação a outros interesses legítimos, ainda que se tenha que apreciar, no caso concreto, eventual conflito com direitos de outros sujeitos de relevância considerável, mediante ponderação (AMIN, 2013, p. 64; ROSSATO; LÉPORE; CUNHA, 2010, p. 98-99).

O STJ, ao julgar demanda referente a acesso a creche por crianças de zero a seis anos, priorizou o direito à educação em face de argumentos de suposta reserva orçamentária e indicou que a aplicação de gastos excessivos com festividades e propaganda governamental, por exemplo, não pode ser suportada como escolhas oponíveis à implementação de direitos fundamentais, conforme disposto:

ADMINISTRATIVO E CONSTITUCIONAL - ACESSO À CRECHE AOS MENORES DE ZERO A SEIS ANOS - DIREITO SUBJETIVO - RESERVA DO POSSÍVEL - TEORIZAÇÃO E CABIMENTO - IMPOSSIBILIDADE DE ARGUIÇÃO COMO TESE ABSTRATA DE DEFESA - ESCASSEZ DE RECURSOS COMO O RESULTADO DE UMA DECISÃO POLÍTICA - PRIORIDADE DOS

\footnotetext{
4 Art. $4^{\circ}$ É dever da família, da comunidade, da sociedade em geral e do poder público assegurar, com absoluta prioridade, a efetivação dos direitos referentes à vida, à saúde, à alimentação, à educação, ao esporte, ao lazer, à profissionalização, à cultura, à dignidade, ao respeito, à liberdade e à convivência familiar e comunitária. Parágrafo único. A garantia de prioridade compreende: a) primazia de receber proteção e socorro em quaisquer circunstâncias; b) precedência de atendimento nos serviços públicos ou de relevância pública; c) preferência na formulação e na execução das políticas sociais públicas; d) destinação privilegiada de recursos públicos nas áreas relacionadas com a proteção à infância e à juventude. (BRASIL, 1990).
} 
DIREITOS FUNDAMENTAIS - CONTEÚDO DO MÍNIMO EXISTENCIAL ESSENCIALIDADE DO DIREITO À EDUCAÇÃO - PRECEDENTES DO STF E STJ [...] 3. Esse estado de escassez, muitas vezes, é resultado de um processo de escolha, de uma decisão. Quando não há recursos suficientes para prover todas as necessidades, a decisão do administrador de investir em determinada área implica escassez de recursos para outra que não foi contemplada. A título de exemplo, o gasto com festividades ou propagandas governamentais pode ser traduzido na ausência de dinheiro para a prestação de uma educação de qualidade. 4. É por esse motivo que, em um primeiro momento, a reserva do possível não pode ser oposta à efetivação dos Direitos Fundamentais, já que, quanto a estes, não cabe ao administrador público preterí-los em suas escolhas. [...] (BRASIL, 2010c).

Não caberia, portanto, ao Poder Público aplicar recursos em segmentos que não levam à materialização de direitos, a exemplo da propaganda institucional, enquanto não houver destinado verbas suficientes para a execução de políticas públicas infantojuvenis necessárias. Pelo mesmo motivo, não pode a Fazenda Pública alegar suposta falta de recursos diante do ajuizamento de ação com o objetivo de obrigar o ente a implementar direito infantojuvenil se os tem para aplicação em áreas não prioritárias.

O descumprimento da prioridade, portanto, é passível de controle jurisdicional e permite que uma série de pedidos sejam feitos, tais como a responsabilização pessoal do administrador pela violação da lei, o investimento de recursos inicialmente alocados em áreas não prioritárias para a promoção dos direitos socioassistenciais infantojuvenis, se isso ainda for possível durante aquele exercício financeiro, ou a inclusão da diferença de recursos que deveria ter sido investida em direitos fundamentais no orçamento do ano seguinte (BARCELLOS, 2007, p. 632).

Há, entretanto, outro tema a ser abordado no que diz respeito à implementação dos direitos sociais, algo que vai além da prioridade orçamentária infantojuvenil. $\bigcirc$ gestor não possui total discricionariedade na elaboração de políticas públicas socioassistenciais para a infância e a juventude. Tal papel cabe, prioritariamente, aos conselhos gestores, conforme se verá, sendo dever do Estado executar as ações deliberadas por aqueles. Nesse sentido, tratar-se-á, a seguir, acerca da força normativa das resoluções aprovadas pelos conselhos de políticas públicas.

\section{Os conselhos gestores e o caráter cogente de suas resoluções}

Os conselhos gestores de políticas públicas compõem espaços de discussão da sociedade civil e dos entes estatais com previsão legal de atuação nas três esferas governamentais: municipal, estadual e federal. Dentre suas funções, podem ser mencionadas as de deliberação e de controle da implementação de políticas públicas, visando materializar direitos sociais (LUCHMANN, 2008, p. 89).

Em razão dos gastos oriundos da realização das políticas públicas, os conselhos gestores detêm também a função de aprovar os planos orçamentários do governo, realizando o controle da quantidade de recursos a ser alocada para implementação de cada uma das ações deliberadas (CHAGAS, 2016, p. 59). 
A implementação de políticas públicas pelo governo, portanto, não pode se dar sem que os conselhos gestores necessariamente deliberem sobre as ações a serem promovidas ou sem que aprovem a inserção das despesas correspondentes aos planos orçamentários, funcionando aqueles como uma instância fundamental na implementação dos direitos sociais.

Interessa observar, ainda, que os conselhos gestores constituem espaço próprio de manifestação da população em comunicação com o governo, fazendo-se aquela representar por entidades organizadas da sociedade civil, tais como membros de associações, de organizações não governamentais, de entidades sindicais e de empresas privadas (INSTITUTO DE PESQUISA ECONÔMICA APLICADA, 2013, p. 29).

A previsão de participação popular na formulação de políticas públicas, aliás, faz parte de uma tendência em expansão, oriunda dos tratados internacionais de direitos humanos, que passa a exigir que os governos priorizem o diálogo com a sociedade civil antes de tomar decisões que possam afetá-la (COURTIS, 2015, p. 12-14).

Dessa forma, a sociedade civil organizada deve ser entendida como participante ativa no debate acerca da implementação de direitos sociais, tais como os direitos socioassistenciais infantojuvenis, fazendo-se representar no âmbito dos conselhos de assistência social e dos conselhos de direitos da criança e do adolescente, com atribuição expressa para discutir como as políticas públicas devem ser concretizadas.

A LOAS prevê, em seu art. 50, II, "participação da população, por meio de organizações representativas, na formulação das políticas e no controle das ações em todos os níveis" (BRASIL, 1993), sendo o espaço próprio para a materialização desse dispositivo legal o conselho de assistência social.

Coadunando com o disposto acima, o item 4.3 da Resolução n. $130^{5}$ do Conselho Nacional de Assistência Social (CNAS), a qual aprovou a Norma Operacional Básica da Assistência Social (NOB SUAS), dispõe ser função dos conselhos gestores aprovar os planos de assistência social e a proposta orçamentária dos recursos destinados a tais ações, oriundos dos fundos especiais.

No âmbito do ECA, de maneira semelhante, o art. 88, II, ${ }^{6}$ dispõe que compete à União, aos Estados, ao Distrito Federal e aos Municípios a criação de conselhos gestores de políticas

\footnotetext{
5 4.3. Deliberação [...] Os Conselhos Estaduais de Assistência Social tem suas competências definidas em legislação específica e deverão no cumprimento desta Norma: [...] b) Aprovar a Política Estadual de assistência Social, elaborada em consonância com a Política Nacional de Assistência Social na perspectiva do SUAS e as diretrizes estabelecidas pelas Conferências de Assistência Social; c) Acompanhar e controlar a execução da Política Estadual de Assistência Social; d) Aprovar o Plano Estadual de Assistência Social e suas adequações; [...] i) Aprovar a proposta orçamentária dos recursos destinados às ações finalísticas de assistência social, alocados no Fundo Estadual de Assistência Social; [...] Os conselhos municipais têm suas competências definidas na LOAS e complementadas por legislação específica e deverão no cumprimento desta norma: [...] b) Aprovar a Política Municipal de Assistência Social, elaborada em consonância com a Política Estadual de Assistência Social na perspectiva do SUAS e as diretrizes estabelecidas pelas Conferências de Assistência Social; c) Acompanhar e controlar a execução da Política Municipal de Assistência Social; d Aprovar o Plano Municipal de Assistência Social e suas adequações; [...] g) Aprovar a proposta orçamentária dos recursos destinados às ações finalísticas de assistência social, alocados no Fundo Municipal de Assistência Social; [...] (BRASIL, 2005).

6 Art. 88. São diretrizes da política de atendimento: [...] II - criação de conselhos municipais, estaduais e nacional dos direitos da criança e do adolescente, órgãos deliberativos e controladores das ações em todos os níveis, assegurada a participação popular paritária por meio de organizações representativas, segundo leis federal, estaduais e municipais. (BRASIL, 1990).
} 
públicas, assegurada a participação popular paritária, voltados à discussão e ao controle das ações governamentais próprias da área de infância e juventude.

Ainda, conforme indica o art. $9^{\circ}$ da Resolução n. $137^{7}$ do Conselho Nacional dos Direitos da Criança e do Adolescente (CONANDA), cabe ao Conselho de Direitos da Criança e do Adolescente elaborar documento acerca do diagnóstico da situação da infância e da adolescência, apontando as maiores carências enfrentadas pela sociedade naquele meio.

Após, tal diagnóstico deve ser incorporado ao Plano de Ação, estabelecendo objetivos, metas e prioridades. Em seguida, encaminha-se o plano ao Poder Executivo para que suas disposições sejam incluídas tanto ao Projeto de Plano Plurianual (PPA) quanto à Lei de Diretrizes Orçamentárias (LDO). Por fim, após sanção da LDO, cabe ao conselho de direitos elaborar Plano de Aplicação, a partir do qual se discute quais políticas públicas devem ser incluídas à Lei Orçamentária Anual (LOA), indicando-se as fontes de receita para realização destas (PEREIRA JÚNIOR, 2012, p. 93-94).

Em razão, portanto, de normas expressas acerca da competência dos conselhos de direitos em realizarem a deliberação de políticas públicas e de controlarem a aplicação dos recursos governamentais nas respectivas áreas de interesse, as resoluções emitidas por aqueles constituem normas cogentes, não podendo a Administração Pública deixar de dar efetividade a elas, conforme já decidido pelo STJ. ${ }^{8}$

A possibilidade de intervenção judicial, então, surge a partir da omissão da Administração Pública em implementar políticas aprovadas pelos conselhos através de resoluções, devendo ser respeitadas as deliberações promovidas tanto pelos conselhos de assistência social quanto pelos conselhos de direitos da criança e do adolescente.

Neste sentido, torna-se possível materializar, por meio da judicialização em face de omissão dos poderes políticos (Executivo e Legislativo), a criação de uma série de serviços, tais como o de república, voltado ao acolhimento suplementar e temporário de jovens egressos de Unidades de Acolhimento.

Conforme será visto, a condenação judicial de ente municipal à criação deste programa só se torna possível em razão de sua regulamentação pelo CNAS e pelo CONANDA de forma conjunta,

\footnotetext{
Art. $9^{\circ}$ Cabe ao Conselho dos Direitos da Criança e do Adolescente, em relação aos Fundos dos Direitos da Criança e do Adolescente, sem prejuízo das demais atribuições: I - elaborar e deliberar sobre a política de promoção, proteção, defesa e atendimento dos direitos da criança e do adolescente no seu âmbito de ação; II - promover a realização periódica de diagnósticos relativos à situação da infância e da adolescência bem como do Sistema de Garantia dos Direitos da Criança e do Adolescente no âmbito de sua competência; III - elaborar planos de ação anuais ou plurianuais, contendo os programas a serem implementados no âmbito da política de promoção, proteção, defesa e atendimento dos direitos da criança e do adolescente, e as respectivas metas, considerando os resultados dos diagnósticos realizados e observando os prazos legais do ciclo orçamentário; IV - elaborar anualmente o plano de aplicação dos recursos do Fundo, considerando as metas estabelecidas para o período, em conformidade com o plano de ação; [...] (BRASIL, 2010a).

8 ADMINISTRATIVO E PROCESSO CIVIL - AÇÂO CIVIL PÚBLICA - ATO ADMINISTRATIVO DISCRICIONÁRIO: NOVA VISÃO. 1. Na atualidade, o império da lei e o seu controle, a cargo do Judiciário, autoriza que se examinem, inclusive, as razões de conveniência e oportunidade do administrador. 2. Legitimidade do Ministério Público para exigir do Município a execução de política específica, a qual se tornou obrigatória por meio de resolução do Conselho Municipal dos Direitos da Criança e do Adolescente. 3. Tutela específica para que seja incluída verba no próximo orçamento, a fim de atender a propostas políticas certas e determinadas. 4. Recurso especial provido. (BRASIL, 2004).
} 
o que demonstra a força normativa de suas resoluções. Antes, porém, interessa compreender como funciona o serviço de república, a fim de identificar sua aptidão à concretização do direito socioassistencial infantojuvenil.

\section{Repúblicas para jovens egressos de unidades de acolhimento que atingiram a maioridade}

A criação e organização de repúblicas para jovens egressos de Unidades de Acolhimento que atingiram a maioridade encontra previsão em mais de um documento aprovado isolada ou conjuntamente pelo CNAS e pelo CONANDA. Destaca-se, porém, o documento intitulado Orientações Técnicas: Serviços de Acolhimento para Crianças e Adolescentes, aprovado pela Resolução Conjunta CNAS/CONANDA n. 1, de 18 de junho de 2009.

Este documento, no item 4.4, discrimina bem o modo como devem funcionar as repúblicas, indicando sua definição, público alvo, organização, número máximo de usuários, características, aspectos físicos do imóvel utilizado, recursos humanos, composição da equipe profissional responsável e infraestrutura e espaço mínimo sugeridos (BRASIL, 2009, p. 94-99).

Diante da maior especificidade dada pelo referido documento, convém transcrever a definição de república efetuada no item 4.4.1 daquele (BRASIL, 2009, p. 94):

Serviço de acolhimento que oferece apoio e moradia subsidiada a grupos de jovens em situação de vulnerabilidade e risco pessoal e social; com vínculos familiares rompidos ou extremamente fragilizados; em processo de desligamento de instituições de acolhimento, que não tenham possibilidade de retorno à família de origem ou de colocação em família substituta e que não possuam meios para auto-sustentação.

Com a estrutura de uma residência privada, deve receber supervisão técnica e localizar-se em áreas residenciais da cidade, seguindo o padrão sócio-econômico da comunidade onde estiverem inseridas, sem distanciar-se excessivamente, do ponto de vista sócio-econômico, da comunidade de origem dos usuários.

A república oferece atendimento durante o processo de construção de autonomia pessoal e possibilita o desenvolvimento de auto-gestão, auto-sustentação e independência. Possui tempo de permanência limitado, podendo ser reavaliado e prorrogado em função do projeto individual formulado em conjunto com o profissional de referência.

Do exposto, resta claro que a criação das repúblicas visa fornecer um período de transição à vida autônoma para o jovem cujo acolhimento nas entidades previstas na Política de Atendimento do ECA durou até que ele completasse a maioridade, constituindo como objetivo da permanência em república a construção de maior capacidade de sustento próprio e de independência após o desligamento da unidade de acolhimento em virtude do alcance dos dezoito anos de idade completos.

Saliente-se que as medidas protetivas especificadas no art. 101 do ECA, dentre as quais se inclui o acolhimento institucional, somente se aplicam a crianças e a adolescentes, conforme 
disposto no art. $98^{9}$ do Estatuto, ou seja, a pessoa só tem direito ao acolhimento previsto no ECA até que complete dezoito anos de idade, momento a partir do qual, segundo o art. $2^{\circ}$ do mesmo diploma, o indivíduo deixa de ser adolescente, o que leva ao seu desligamento da entidade.

O público alvo, em geral, das repúblicas, portanto, constitui-se de pessoas que, por motivos de negligência, maus tratos, abuso ou de outras violações de direitos perpetradas pela sua família, pelo Estado ou pela sociedade, nos termos do art. 98 do ECA, foram submetidas, enquanto eram crianças ou adolescentes, a medida protetiva de acolhimento institucional, sem que se obtivesse sucesso, por razões diversas, em recolocá-las ao lar de origem ou em família substituta.

Ainda no âmbito do documento Orientações Técnicas: Serviços de Acolhimento para Crianças e Adolescentes, estipulou-se como regra geral que o público alvo das repúblicas deve ser formado por jovens de dezoito a vinte e um anos de idade cujos vínculos familiares tenham sido potencial ou efetivamente rompidos e que não tenham condições de sustento próprio, voltando-se prioritariamente àqueles que foram desligados de programa de acolhimento institucional.

No mais, o serviço deve ser organizado em unidades femininas e masculinas com capacidade máxima de seis jovens para cada (BRASIL, 2009, p. 94). Além disso, o grupo de jovens residente em república deve contar com apoio de equipe técnica, tanto para ajudá-los na gestão coletiva da moradia quanto para que sejam fortalecidas aptidões e capacidades referentes a atividades culturais, esportivas e profissionais, cabendo à referida equipe socioassistencial buscar, em conjunto com o interessado, cursos profissionalizantes e programas de inserção no mercado de trabalho (BRASIL, 2009, p. 95-96).

As unidades de repúblicas devem, ainda, funcionar em espaços destinados ao uso residencial, sem que se realize menção ao tipo de serviço que está sendo ofertado ali, a fim de evitar discriminação, fazendo-se necessário seguir as recomendações mínimas de infraestrutura informadas no documento aprovado pela Resolução Conjunta CNAS/CONANDA n. 1, de 18 de junho de 2009 (BRASIL, 2009, p. 99).

Tem-se, portanto, que as repúblicas devem funcionar como serviço de proteção social voltadas prioritariamente a jovens egressos de Unidades de Acolhimento que atingiram a maioridade, visando a conquista de maior autonomia e independência pela inserção no mercado de trabalho e pelo desenvolvimento de atividades culturais, sociais e esportivas, constando a organização de tais instituições em resoluções aprovadas pelo CNAS e pelo CONANDA.

A viabilização do serviço de república, em conformidade com as diretrizes acima apresentadas, constitui, assim, oportunidade de concretização de um direito socioassistencial infantojuvenil, apto à implementação em virtude de resolução debatida e aprovada por conselhos gestores.

\footnotetext{
9 Art. 98. As medidas de proteção à criança e ao adolescente são aplicáveis sempre que os direitos reconhecidos nesta Lei forem ameaçados ou violados:

I - por ação ou omissão da sociedade ou do Estado;

II - por falta, omissão ou abuso dos pais ou responsável;

III - em razão de sua conduta. (BRASIL, 1990).
} 
Não sendo o serviço oferecido pelo município, faz-se necessário que órgão com legitimidade para ajuizamento de ação civil pública judicialize a questão, tomando como base a força normativa das deliberações promovidas pelos conselhos gestores de assistência social e infantojuvenis e a aplicação imediata de direitos fundamentais socioassistenciais.

\section{Judicialização frente à omissão municipal em criar repúblicas para jovens}

A judicialização da política, tema que inclui o controle jurisdicional de políticas públicas, é próprio dos regimes democráticos, servindo como instrumento de preservação dos direitos fundamentais e de manutenção do funcionamento adequado das instituições públicas (STRECK, 2016, p. 724).

Não se pode, portanto, negar a possibilidade de atuação judicial frente à omissão dos demais poderes institucionais. A judicialização da política se faz necessária para a preservação dos interesses constitucionais, devendo a sociedade civil e o próprio governo, entretanto, coibir eventuais exageros promovidos por juízes.

Como visto ao longo do estudo, o controle jurisdicional de políticas públicas pode ser realizado em diversas modalidades, sendo viável sua realização, no que diz respeito ao tema central desse estudo, tanto em razão da necessidade de dar efetividade à garantia de prioridade infantojuvenil, prevista no art. $4^{\circ}$ do ECA (BRASIL, 1990), quanto pelo caráter cogente das resoluções aprovadas pelos conselhos gestores.

Conforme examinado em tópico anterior, existe previsão de oferta do serviço de repúblicas em resoluções aprovadas pelo CNAS e pelo CONANDA. Apesar disso, nem todos os Municípios seguem as recomendações dos conselhos referidos, dando ensejo ao ajuizamento de ação em face do ente municipal visando à criação do serviço sob os argumentos a seguir expostos.

Em primeiro lugar, merece destaque o fato de que a criação de repúblicas tem por objeto fornecer serviço socioassistencial à população jovem cujos vínculos familiares foram rompidos, inexistindo, ainda que de forma temporária, possibilidade de reinserção na família de origem, sendo uma das características de maior relevo de tal serviço a disponibilização de período de transição para uma vida autônoma pela integração no mercado de trabalho e na vida comunitária.

Diante de tal perspectiva, torna-se possível visualizar as repúblicas como serviços, oriundos de políticas públicas, a serem desenvolvidos como instrumento de materialização do direito fundamental à assistência social, pautados principalmente no art. 203, III, da CF,10 no art. 20 , I, "c", da LOAS ${ }^{11}$ e no art. 15, V, do EJ.

\footnotetext{
$\overline{10}$ Art. 203. A assistência social será prestada a quem dela necessitar, independentemente de contribuição à seguridade social, e tem por objetivos: [...] III - a promoção da integração ao mercado de trabalho; [...] (BRASIL, 1998).

11 Art. $2^{\circ} \mathrm{A}$ assistência social tem por objetivos: I - a proteção social, que visa à garantia da vida, à redução de danos e à prevenção da incidência de riscos, especialmente: [...] c) a promoção da integração ao mercado de trabalho; [...] (BRASIL, 1993).
} 
Além disso, por mais que as repúblicas estejam voltadas a jovens, e não a crianças e a adolescentes, não se pode deixar de notar que este serviço representa uma continuidade em relação à política de atendimento prevista no ECA, cujo objetivo é efetivar a proteção integral da população infantojuvenil em situação de violação de direitos.

Vale recordar que o ECA estabelece situação na qual se estende sua aplicação a jovens de dezoito a vinte e um anos de idade. Diz o art. $2^{\circ}$ do referido diploma que se considera como adolescente a pessoa entre doze e dezoito anos de idade. Apesar disso, o parágrafo único do mesmo dispositivo estabelece que "nos casos expressos em lei, aplica-se excepcionalmente este Estatuto às pessoas entre dezoito e vinte e um anos de idade." (BRASIL, 1990).

Ademais, o próprio ECA, ao tratar da medida socioeducativa de internação, aponta que esta poderá ser aplicada até os vinte e um anos de idade, conforme disposto em seu art. 121, \$ $5^{\circ}$. Ora, se a extensão da medida socioeducativa de internação alcança, no próprio Estatuto, idade superior a dezoito anos, tendo em vista a necessidade de ressocialização do adolescente em conflito com a lei, não há como afirmar que a medida de instalação de repúblicas esteja em desacordo com o ECA, uma vez que a oferta de tal serviço busca dar continuidade à finalidade das instituições de acolhimento nas quais viviam adolescentes sob medida de proteção.

Desse modo, ainda que falte expressa menção na lei federal a este respeito, sendo matéria de lege ferenda, pode-se recorrer ao princípio hermenêutico Ubi eadem ratio ibi eadem legis dispositivo"onde existe a mesma razão, aí se aplica o mesmo dispositivo legal". Outros argumentos, apontados abaixo, somam-se a tal alegação.

Não seria razoável, assim como não se compatibiliza com os fundamentos e os objetivos constitucionais de preservação da dignidade humana (art. 1º, III, CF) e de erradicação da marginalização e redução das desigualdades sociais (art. $3^{\circ}$, III, CF), permitir que o jovem acolhido institucionalmente seja desligado da política de atendimento tão somente pelo fato de ter atingido a maioridade, não dispondo de qualquer auxílio por parte do Estado.

Em 13 de julho de 2010 entrou em vigor a Emenda Constitucional n. 65, a qual alterou o Capítulo VII do Título VIII da CF para que passasse a se denominar "da Família, da Criança, do Adolescente, do Jovem e do Idoso" (BRASIL, 2010b), fazendo alusão, portanto, aos jovens, que antes não eram mencionados pelo art. 227 da CF.

Com isso, a CF passou a prever absoluta prioridade ao atendimento do "direito à vida, à saúde, à alimentação, à educação, ao lazer, à profissionalização, à cultura, à dignidade, ao respeito, à liberdade e à convivência familiar e comunitária" também do jovem, estabelecendo, ainda, a necessidade de criação do "estatuto da juventude, destinado a regular os direitos dos jovens" (BRASIL, 2010c), a partir, respectivamente, do caput e do $\$ 8^{\circ}$, I, do art. $227 .{ }^{12}$

\footnotetext{
${ }^{12}$ Art. 227. É dever da família, da sociedade e do Estado assegurar à criança, ao adolescente e ao jovem, com absoluta prioridade, o direito à vida, à saúde, à alimentação, à educação, ao lazer, à profissionalização, à cultura, à dignidade, ao respeito, à liberdade e à convivência familiar e comunitária, além de colocá-los a salvo de toda forma de negligência, discriminação,
} 
O Estatuto da Juventude (EJ), por sua vez, foi instituído pela promulgação da Lei n. 12.852, de 5 de agosto de 2013, prevendo, dentre outros, os princípios à "promoção da autonomia e emancipação dos jovens" (art. $2^{\circ}, \mathrm{I}$ ), ao "reconhecimento do jovem como sujeito de direitos universais, geracionais e singulares" (art. $2^{\circ}, \mathrm{IV}$ ) e à "promoção do bem-estar, da experimentação e do desenvolvimento integral do jovem." (art. 2 , V) (BRASIL, 2013).

Além disso, o mesmo estatuto previu como diretriz geral de políticas públicas a ampliação de "alternativas de inserção social do jovem, promovendo programas que priorizem o seu desenvolvimento integral e participação ativa nos espaços decisórios" (art. 3, III), o "atendimento de acordo com suas especificidades perante os órgãos públicos e privados prestadores de serviços à população, visando ao gozo de direitos simultaneamente nos campos da saúde, educacional, político, econômico, social, cultural e ambiental" (art. $3^{\circ}$, IV) e a "adoção de políticas públicas voltadas para a promoção do estágio, aprendizagem e trabalho para a juventude." (art. 15, V) (BRASIL, 2013).

Tem-se, portanto, que, a partir da Emenda Constitucional n. 65 de 2010, com a inclusão do jovem no art. 227 da CF, a população juvenil passou a gozar de extensão da aplicação da proteção integral voltada a crianças e a adolescentes, naquilo que for congruente com o EJ, merecendo, proteção estatal em conformidade com os princípios e diretrizes mencionados, dentre os quais se ressaltou a inserção em programas que priorizem a promoção da autonomia, o gozo de direitos sociais (nos quais se inclui o direito à assistência social) e o desenvolvimento integral de sua personalidade, fatores estes que podem ser concretizados por meio da criação de repúblicas.

No que diz respeito à criação das repúblicas, tal encargo deve ser suportado pelo ente municipal, uma vez que os arts. $15, \mathrm{~V},{ }^{13}$ e 23 , IS $1^{\circ}$ e $2^{\circ},{ }^{14}$ da LOAS estabeleceram competência ao município para a materialização dos serviços socioassistenciais, assim como o fez o art. $43^{15}$ do EJ.

Desse modo, inexistindo prestação de serviço de república pelo município, cabe aos legitimados (Ministério Público, Defensoria Pública ou associação de defesa dos direitos dos jovens) ajuizar ação civil pública, com base no art. $1^{\circ}$, IV, e no art. 5 , I, II e V, ambos da Lei n. 7.347 de 1985, visando à condenação do ente municipal à obrigação de fazer consistente na criação do serviço mencionado, com base nos requisitos mínimos previstos nas resoluções do CNAS e do CONANDA.

Ressalte-se que a possibilidade de judicialização da política pública de república encontra respaldo no fato de ser este o meio de concretização dos direitos fundamentais à assistência social e à proteção integral, gozando o controle judicial de respaldo social e democrático (ALBUQUERQUE,

exploração, violência, crueldade e opressão. [...] $\int 8^{\circ}$ A lei estabelecerá: I - o estatuto da juventude, destinado a regular os direitos dos jovens; [...] (BRASIL, 2010c).

${ }^{13}$ Art. 15. Compete aos Municípios: [...] V - prestar os serviços assistenciais de que trata o art. 23 desta lei. [...] (BRASIL, 1993).

${ }^{14}$ Art. 23. Entendem-se por serviços socioassistenciais as atividades continuadas que visem à melhoria de vida da população e cujas ações, voltadas para as necessidades básicas, observem os objetivos, princípios e diretrizes estabelecidos nesta Lei. (BRASIL, 1993).

15 Art. 43. Compete aos Municípios: [...] III - criar, desenvolver e manter programas, ações e projetos para a execução das políticas públicas de juventude; [...] (BRASIL, 2013). 
2013, p. 137), na medida em que atende aos fins de redução da desigualdade previstos na CF (art. $3^{\circ}$, III) (BRASIL, 1988).

Além disso, convém mencionar que, apesar do referido caráter de norma programática, principalmente no que diz respeito às ações governamentais na área de assistência social previstas nos arts. 203 e 204 da CF, o CNAS e o CONANDA regulamentaram satisfatoriamente o modo como devem funcionar as repúblicas.

Assim, não merece prosperar eventual argumento de que o Poder Judiciário, ao dar efetividade ao comando regulatório, estaria se imiscuindo em atividade do Poder Legislativo, afinal o próprio ordenamento jurídico atribuiu aos conselhos gestores competência para a deliberação de políticas públicas, inclusive sob a ótica da legitimidade da participação cidadã na tomada de decisões na vida pública.

Diante de todo o exposto, torna-se possível afirmar que a criação de repúblicas para jovens a partir de determinação judicial está em consonância com o ordenamento jurídico, uma vez que busca, além de concretizar direitos, dar efetividade a resoluções aprovadas pelo CNAS e pelo CONANDA, os quais possuem atribuição legal para deliberar acerca de políticas públicas socioassistenciais e infantojuvenis.

\section{Conclusão}

Os resultados oferecidos pela pesquisa permitem concluir que os direitos fundamentais socioassistenciais da população infantojuvenil, por mais que constituam direitos de cunho social e se configurem como normas programáticas, devem ser dotados de efetividade.

A simples constatação do caráter de norma programática não permite aos entes federativos que se omitam ao dever constitucional de promover direitos. Eventual omissão pode vir a ser suprida por meio de intervenção do Poder Judiciário, ainda mais diante da existência de documentos normativos que regulamentam políticas determinadas, como é o caso da prestação do serviço de repúblicas.

Tal controle judicial, porém, não se pauta em temerária invasão das atribuições administrativas e legislativas dos poderes democráticos, e sim em cumprimento de preceitos legais que estabelecem a necessidade de deliberação das políticas públicas pela sociedade civil.

Nesse âmbito, sobressai a necessidade de efetivação de direitos fundamentais e de cumprimento das medidas aprovadas por conselhos gestores, responsáveis legais pela discussão e pelo controle da implementação de políticas em áreas como assistência social e proteção infantojuvenil.

A previsão legal de deliberação de políticas públicas pelos conselhos traz consequências jurídicas, dentre as quais a necessidade de observação das resoluções aprovadas por tais colegiados como atos que vinculam a Administração Pública, não podendo o gestor deixar de cumprir aquilo que foi regulamentado. 
Sob a ótica da implementação dos direitos sociais, portanto, não deve o operador do direito se limitar à análise de leis em sentido estrito, ou seja, aquelas aprovadas pelo Poder Legislativo. Exigese, nesse contexto, que sejam considerados os mais diversos documentos emitidos pelas instituições competentes, a exemplo das resoluções aprovadas por conselhos gestores.

A integração das mencionadas resoluções à prática jurídica da materialização dos direitos fundamentais não só efetiva os comandos legais, como confere legitimidade às ações governamentais, cujas decisões administrativas em temas como políticas de assistência social voltadas à população infantojuvenil devem ser tomadas em conjunto com a sociedade civil.

Além disso, a consideração pelo Poder Judiciário de decisões tomadas pela sociedade civil, representada de forma democrática pelos mais diversos atores no âmbito dos conselhos, tende a fortalecer o Estado Democrático de Direito, fornecendo aos cidadãos uma oportunidade de participação nas ações governamentais que vai além da prática político-eleitoral.

Nesse contexto, a adoção de medidas judiciais com o intuito de obrigar a Administração Pública a oferecer o serviço de república regulamentado pelos conselhos competentes é plenamente plausível. O controle jurisdicional, nesse caso, simplesmente corresponde ao dever do Judiciário de conferir efetividade ao ordenamento jurídico, materializando direito socioassistencial infantojuvenil.

\section{Referências}

ALBUQUERQUE, Felipe Braga. Direito e política: pressupostos para a análise de questões políticas pelo judiciário à luz do princípio democrático. Florianópolis: Conceito Editorial, 2013.

AMIN, Andréa Rodrigues. Princípios orientadores do direito da criança e do adolescente. In: MACIEL, Katia Regina Ferreira Lobo Andrade (org.). Curso de direito da criança e do adolescente: aspectos teóricos e práticos. 6. ed. São Paulo: Saraiva, 2013. p. 59-72.

BARCELLOS, Ana Paula de. Constitucionalização das políticas públicas em matéria de direitos fundamentais: o controle político-social e o controle jurídico no espaço democrático. In: SOUZA NETO, Cláudio Pereira de; SARMENTO, Daniel (org.). A constitucionalização do direito: fundamentos teóricos e aplicações específicas. Rio de Janeiro: Lumen Juris, 2007. p. 599-635.

BONAVIDES, Paulo. Curso de direito constitucional. 15. ed. São Paulo: Malheiros, 2004.

BRASIL. Conselho Nacional de Assistência Social; Conselho Nacional dos Direitos da Criança e do Adolescente. Resolução Conjunta CNAS/CONANDA n. 1, de 18 de junho de 2009. Aprova o documento Orientações Técnicas: Serviços de Acolhimento para Crianças e Adolescentes. Diário Oficial da União, Brasília, DF, 2 jul. 2009.

BRASIL. Conselho Nacional de Assistência Social. Resolução CNAS n. 130, de 15 de julho de 2005. Aprova a Norma Operacional Básica da Assistência Social - NOB SUAS. Diário Oficial da União, Brasília, DF, 25 jul. 2005. 
BRASIL. Conselho Nacional dos Direitos da Criança e do Adolescente. Resolução CONANDA n. 137, de 21 de janeiro de 2010. Dispõe sobre os parâmetros para a criação e o funcionamento dos Fundos Nacional, Estaduais e Municipais dos Direitos da Criança e do Adolescente e dá outras providências. Diário Oficial da União, Brasília, DF, 4 mar. 2010a.

BRASIL. Constituição (1988). Emenda constitucional n. 65, de 13 de julho de 2010. Altera a denominação do Capítulo VII do Título VIII da Constituição Federal e modifica o seu art. 227, para cuidar dos interesses da juventude. Diário Oficial da União, Brasília, DF, 14 jul. 2010b.

BRASIL. Constituição: República Federativa do Brasil de 1988. Brasília, DF: Senado Federal, 1988.

BRASIL. Lei n. 8.069, de 13 de julho de 1990. Dispõe sobre o Estatuto da Criança e do Adolescente e dá outras providências. Diário Oficial da União, Brasília, DF, 16 jul. 1990.

BRASIL. Lei n. 8.742, de 7 de dezembro de 1993. Dispõe sobre a organização da Assistência Social e dá outras providências. Diário Oficial da União, Brasília, DF, 8 dez. 1993.

BRASIL. Lei n. 12.852, de 5 de agosto de 2013. Institui o Estatuto da Juventude e dispõe sobre os direitos dos jovens, os princípios e diretrizes das políticas públicas de juventude e o Sistema Nacional de Juventude - SINAJUVE. Diário Oficial da União, Brasília, DF, 6 ago. 2013.

BRASIL. Superior Tribunal de Justiça. (2. Turma). REsp n. 493.811/SP. Relatora: Ministra Eliana Calmon, Julgamento em 11 de novembro de 2003. Diário da Justiça Eletrônico, Brasília, DF, 15 mar. 2004.

BRASIL. Superior Tribunal de Justiça. (2. Turma). REsp n. 1.185.474/SC. Relator: Ministro Humberto Martins. Diário da Justiça Eletrônico, Brasília, DF, 29 abr. 2010c.

BUCCI, Maria Paula Dallari. O conceito de política pública em direito. In: BUCCI, Maria Paula Dallari (org.). Reflexões sobre o conceito jurídico. São Paulo: Saraiva, 2006. p. 1-49.

BULOS, Uadi Lammêgo. Curso de direito constitucional. 7. ed. São Paulo: Saraiva, 2012.

CASTRO, Carlos Roberto Siqueira. A constituição aberta e os direitos fundamentais: ensaios sobre o constitucionalismo pós-moderno e comunitário. Rio de Janeiro: Forense, 2010.

CHAGAS, Francisco Yrallyps Mota. Representação política e participação social: uma abordagem a partir da experiência dos conselhos de políticas públicas e das conferências nacionais. 2016. 90 f. Dissertação (Mestrado em Direito) - Faculdade de Direito, Universidade Federal do Ceará, Fortaleza, 2016.

COURTIS, Cristhian. Democracia, administración pública y derechos sociales. Espaço Jurídico Journal of Law, Joaçaba: Editora Unoesc, v. 16, n. 1, p. 7-16, jan./jun. 2015. Disponível em: https:// editora.unoesc.edu.br/index.php/espacojuridico/article/view/6518/3763. Acesso em: 17 set. 2018.

INSTITUTO DE PESQUISA ECONÔMICA APLICADA. Conselhos Nacionais: perfil e atuação dos conselheiros: Relatório de pesquisa. Brasília, DF: Ipea, 2013.

JORGE NETO, Nagibe de Melo. O controle jurisdicional das políticas públicas: concretizando a democracia e os direitos sociais fundamentais. Salvador: Jus Podivm, 2009. 
LOPES, Emília. A institucionalização de crianças e adolescentes à luz do direito fundamental à convivência familiar e comunitária: uma análise sociojurídica da implementação do acolhimento institucional no Município de Fortaleza-CE. 2012. 165 f.

Dissertação (Mestrado em Direito Constitucional) - Universidade de Fortaleza, Fortaleza, 2012.

LUCHMANN, Lígia Helena Hahn. Participação e representação nos conselhos gestores e no orçamento participativo. Caderno CHR, Salvador, v. 21, n. 52, p. 87-97, jan./abr. 2008.

PEREIRA JÚNIOR, Marcus Vinícius. Orçamento e políticas públicas infantojuvenis: fixação dos planos ideais de atuação para os atores do sistema de garantia de direitos das crianças e adolescentes (SGD). Rio de Janeiro: Forense, 2012.

ROSSATO, Luciano Alves; LÉPORE, Paulo Eduardo; CUNHA, Rogério Sanches. Estatuto da Criança $e$ do Adolescente comentado. São Paulo: Revista dos Tribunais, 2010.

SARLET, Ingo Wolfgang. A eficácia dos direitos fundamentais: uma teoria geral dos direitos fundamentais na perspectiva constitucional. 10. ed. Porto Alegre: Livraria do Advogado, 2011.

STRECK, Lenio Luiz. Entre o ativismo e a judicialização da política: a difícil concretização do direito fundamental a uma decisão judicial constitucionalmente adequada. Espaço Jurídico Journal of Law, Joaçaba: Editora Unoesc, v. 17, n. 3, p. 721-732, set./dez. 2016. Disponível em: http://editora. unoesc.edu.br/index.php/espacojuridico/article/view/12206/pdf. Acesso em: 17 set. 2018. 
